\title{
2217. Cyclic testing of reinforced concrete columns with double or one-side headed shear reinforcement
}

\author{
Taehun Ha ${ }^{1}$, Sungho Lee ${ }^{2}$, Sung-Chul Chun ${ }^{3}$ \\ ${ }^{1,2}$ Architectural Engineering Research Team, Daewoo E\&C, Seoul, Korea \\ ${ }^{3}$ Division of Architecture and Urban Design, Incheon National University, Incheon, Korea \\ ${ }^{3}$ Corresponding author \\ E-mail: ${ }^{1}$ taehun.ha@gmail.com, ${ }^{2}$ sungho.lee@daewooenc.com, ${ }^{3}$ scchun@inu.ac.kr \\ Received 12 April 2016; received in revised form 6 July 2016; accepted 18 July 2016 \\ DOI https://doi.org/10.21595/jve.2016.17421
}

\begin{abstract}
The effectiveness of single-leg crossties that were anchored by heads in reinforced concrete columns was assessed. Seven reinforced concrete columns were tested under reversed cyclic loading with a $10 \%$ axial load of the nominal axial capacity of the columns. Four columns were designed to fail in a flexural mode, and three columns were designed to fail in a shear mode. The main variable was the anchorage type of crossties: conventional crossties that were anchored with $135^{\circ}$ and $90^{\circ}$ hooks, crossties that were anchored with one-side head and one-side $180^{\circ}$ hook, and crossties that were anchored with double heads. The test results indicate that the hysteretic behavior of the columns with crossties that were anchored by double heads or one-side head was similar or superior to the columns with conventional crossties anchored by hooks in terms of ductility and energy dissipation. After the cover concrete spalled, the $90^{\circ}$ hooks inevitably opened and the column longitudinal bars buckled. However, the heads could delay the buckling of the column bars and the columns could maintain their capacities until $8 \%$ drift ratio for the columns that were designed to fail in a flexural mode. For the columns that were designed to fail in a shear mode, all columns showed similar behaviors and had identical strengths. The columns with the headed crossties had smaller crack widths than the columns with conventional crossties because the headed crossties well confined the core concrete under severe shear deformation. The test results show that headed crossties can effectively confine the column bars and core concrete of the columns: therefore, the ductility and energy dissipation capacity of the columns were improved.
\end{abstract}

Keywords: headed shear reinforcement, concrete column, crosstie, standard hook.

\section{Introduction}

Transverse reinforcement in reinforced concrete (RC) columns provides confinement to the core concrete, prevents premature buckling of the longitudinal reinforcing bars, and serves as shear reinforcement [1]. Under seismic loading, the spalling of the cover concrete can be extensive and the strength and ductility of RC columns significantly depend on the effectiveness of the transverse reinforcement on the three roles.

The use of headed bars as crossties offers many advantages. Heads that are properly connected and adequately sized can enable the development of tensile strength of the bar at the bar extremities, unlike crossties with standard $90^{\circ}$ and $135^{\circ}$ hooks. Using headed reinforcing bars reduces reinforcement congestion and can make fabricating the reinforcing cages easier. In addition, the contribution of the head size and rigid head-to-bar connection can increase the reinforcement's confining effect [1-3]. However, the cost of the headed shear reinforcement is obviously higher than that of the crossties with standard hooks. This disadvantage may be mitigated by using crossties with one-side head and one-side $180^{\circ}$ hook. The $180^{\circ}$ hook has the same anchorage capacity to the head because the $180^{\circ}$ hook does not open under reversed cyclic loading. The crossties with one-side head and one-side $180^{\circ}$ hook can be fabricated as easily as the crossties with double heads. Moreover, the $180^{\circ}$ hook can reduce the interference of hook's tail on the column bars. Until now, the structural behavior of the crossties with one-side head and one-side $180^{\circ}$ hook has not been reported. 
Although there are a number of experimental studies on columns with hoops, ties, and crossties, there are only a few experimental results on columns [1, 4] with headed reinforcement. Moreover, only double headed bars were used in the previous studies [1, 3, 4], and the effectiveness of headed bars was investigated in columns or walls that were subjected to monotonic axial loading $[1,3]$ or in columns that were designed to fail in a flexural mode subjected to cyclic loading [4]. The reported study in this paper is aimed at investigating the confining effect of double or one-side headed bars that serve as crossties in RC columns, which are subjected to cyclic lateral loading with a constant axial load. In addition, the columns were designed to fail in two types of flexural and shear modes to clearly assess the shear resistance of headed bars.

\section{Test program}

Seven reinforced concrete columns were tested under reversed cyclic loading with a $10 \%$ axial load of the nominal axial capacity of the columns. Four columns were designed to fail in a flexural mode (hereafter flexural tests), and three columns were designed to fail in a shear mode (hereafter shear tests). All columns had a cross section of $800 \times 550 \mathrm{~mm}$ as shown in Fig. 1, and the distances between the critical points and the loading points were 2,200 $\mathrm{mm}$ and 1,100 $\mathrm{mm}$ for the flexural tests and shear tests, respectively, as shown in Fig. 2. To access the effectiveness of crossties, the number of crossties was designed to be more than the legs of a hoop and, therefore, at least three crossties were required in a layer. The sectional dimension was determined to place three crossties in a layer. The aspect ratios of columns are 4 and 2 for the flexural tests and shear tests, respectively. The aspect ratios and vertical spacing of transverse reinforcement were determined to ensure the intended failure mode of flexure or shear.

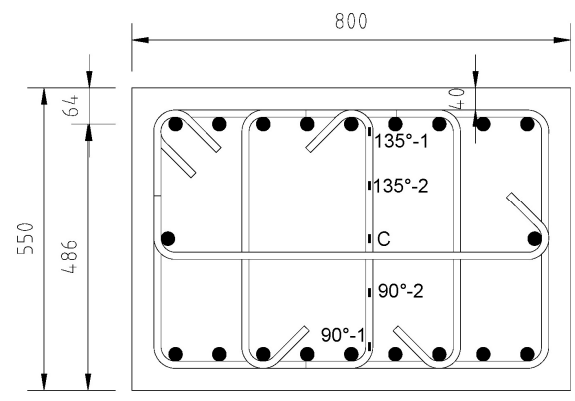

a) FC

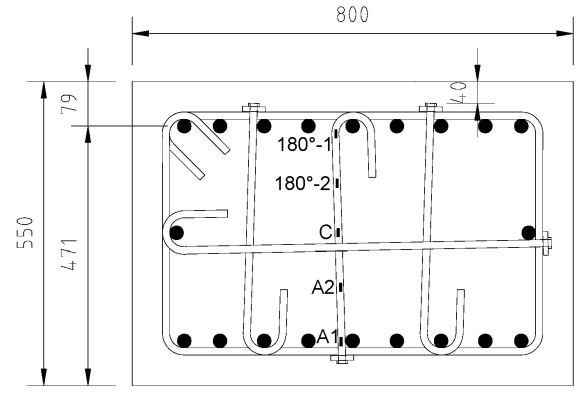

c) FMC

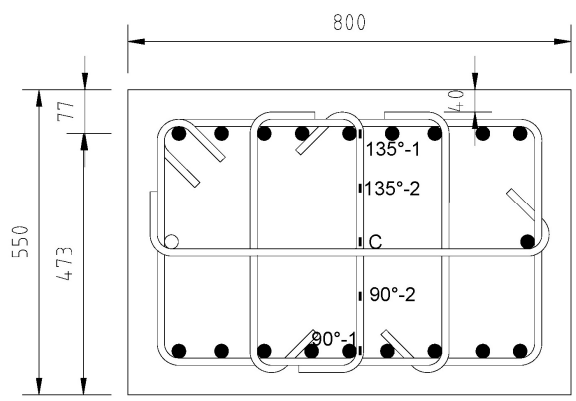

b) FC-1

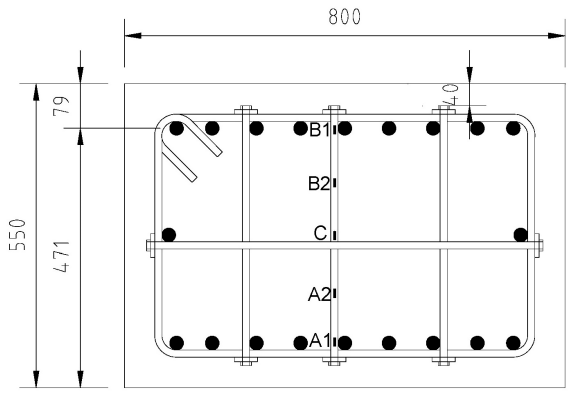

d) FM

Fig. 1. Column sections of the flexural tests

The main variable was the anchorage type of crossties as shown in Fig. 1: FC and SC had conventional crossties that were anchored with $135^{\circ}$ and $90^{\circ}$ hooks; FC-1 had identical conventional crossties as FC and SC, but the hooks enclosed the hoops instead of enclosing the longitudinal bars; FM and SM had double headed crossties that replaced conventional crossties, and the heads enclosed the hoops; and the crossties of FMC and SMC were anchored by one-side 
head and one-side $180^{\circ}$ hook. In the specimen nomenclature, $\mathrm{F}$ and $\mathrm{S}$ represent the flexure and shear tests, respectively; $\mathrm{C}$ indicates a conventional anchorage using standard hooks; and $\mathrm{M}$ indicates a mechanical anchorage using heads. The flexural tests consist of four specimens of FC, FC-1, FMC, and FM and the shear tests consist of three specimens of SC, SMC, and SM. There is a notably small difference between FC and FC-1 that the conventional hooks enclose either the longitudinal bars or the hoops. This difference may affect the effectiveness of confining the core concrete and preventing buckling of the longitudinal bars; therefore, only FC-1 was included in the flexural tests.

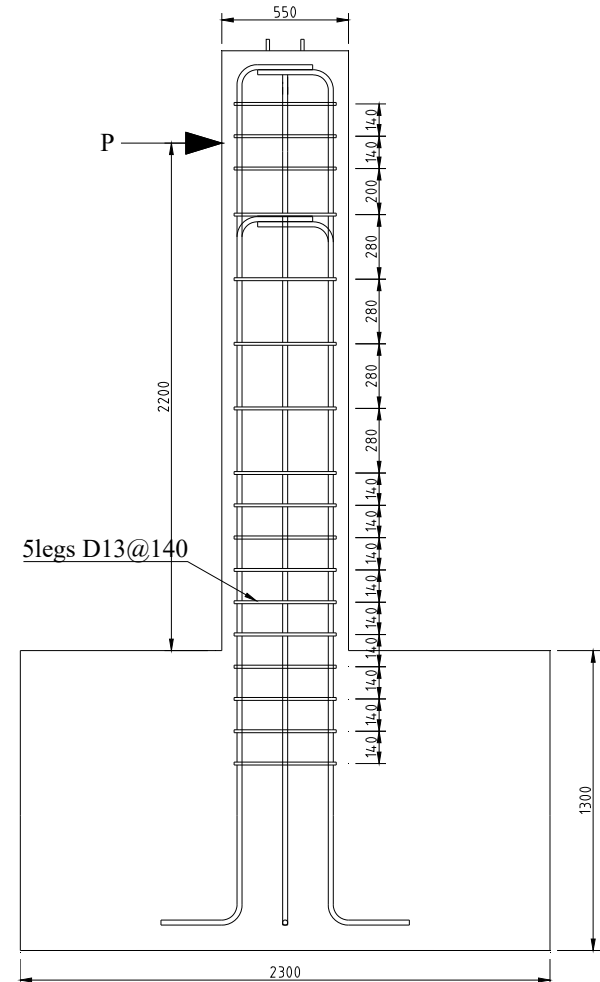

a) Flexural tests

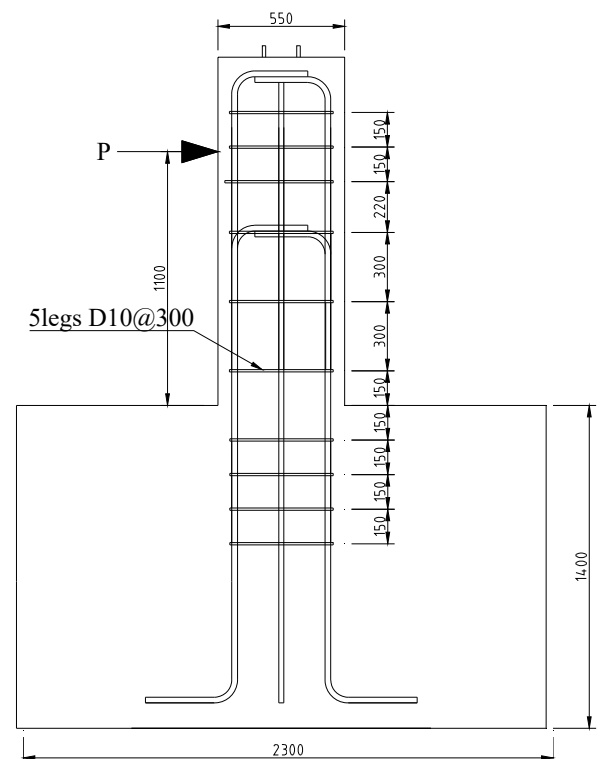

b) Shear tests

Fig. 2. Elevations of the specimens

The headed shear reinforcement conformed to ASTM A970/A970M-15[5] and had circular heads. The diameters of the heads were 35 and $40 \mathrm{~mm}$ for 10 and $13 \mathrm{~mm}$-diameter bars, respectively, so that the net bearing area of the heads should be almost $9 A_{b}$ according to 20.5 of ACI 318-14 [6]. The thicknesses of the heads were 6 and $8 \mathrm{~mm}$ for 10 and $13 \mathrm{~mm}$-diameter bars, respectively. The attachment of the heads to the re-bar was accomplished through threads conforming to 1.1.3 of ASTM A970-15/A970M-15.

Twenty longitudinal bars of $22 \mathrm{~mm}$-diameter $(\rho=1.76 \%)$ were placed for the flexural tests as shown in Fig. 1 and twenty longitudinal bars of $25 \mathrm{~mm}$-diameter $(\rho=2.30 \%)$ were placed for the shear tests. The measured yield strengths of $22 \mathrm{~mm}$ and $25 \mathrm{~mm}$ bars were 412 and $409 \mathrm{MPa}$, respectively. As transverse reinforcement, five legs of $13 \mathrm{~mm}$-diameter bars were placed at 140 $\mathrm{mm}$ vertical spacing in the flexural tests and five legs of $10 \mathrm{~mm}$-diameter bars were placed at 300 $\mathrm{mm}$ vertical spacing in the shear tests as shown in Figs. 1 and 2. The measured yield strength of the $10 \mathrm{~mm}$ and $13 \mathrm{~mm}$ bars were 509 and $388 \mathrm{MPa}$, respectively. The wide vertical spacing of the shear tests was designed for the intended shear failure. The specimens conformed to ACI 318-14 [6] except the vertical spacing of transverse reinforcement of the shear tests. The compressive 
strength of the concrete was $30.6 \mathrm{MPa}$ on the test date.

The clear cover was $40 \mathrm{~mm}$ which was measured to the head according to 20.6.1.3 and R25.4.4.1 of ACI 318-14. Due to the head, the effective depths were changed as shown in Fig. 1. The effective depth of FMC and FM was reduced to $471 \mathrm{~mm}$ and the difference is $3.09 \%$ compared with $486 \mathrm{~mm}$ of FC. Consequently, the flexural strengths of the columns were also changed which were summarized in Table 1. The design strength of FMC and FM is $403 \mathrm{kN}$ which is $97.6 \%$ of the design strength of FC. The difference of the design strength is only $2.4 \%$ which is less than the difference of the effective depth because of the existence of axial force.

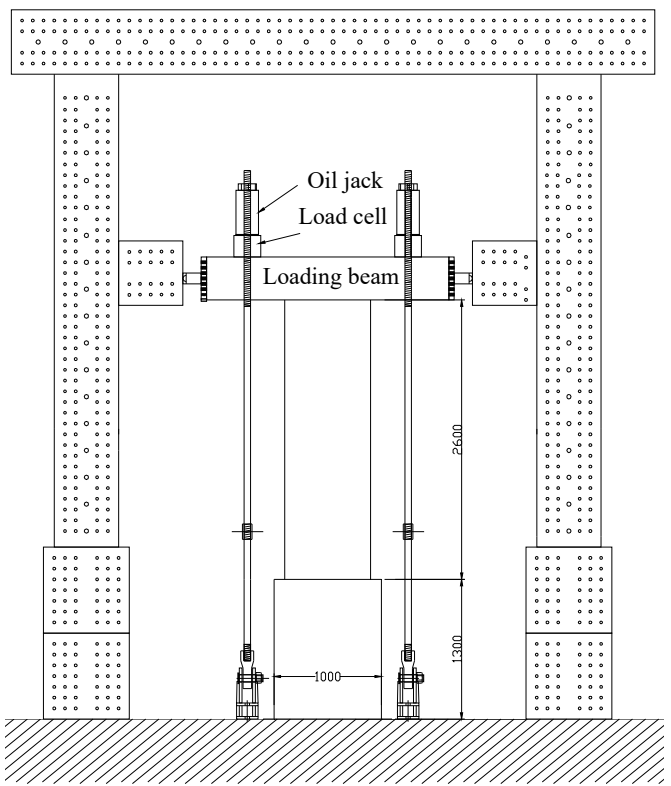

a) Front view

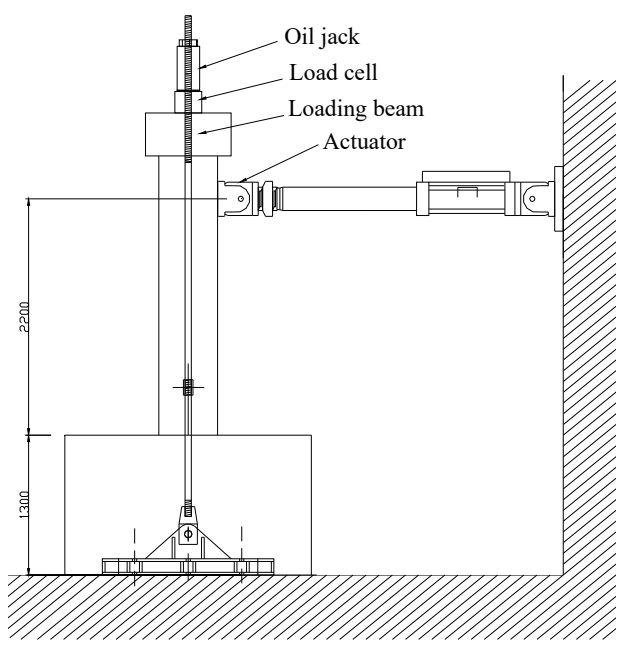

b) Side view

Fig. 3. Test setup for the flexural tests (In side view, the strong frames are invisible for clarity)

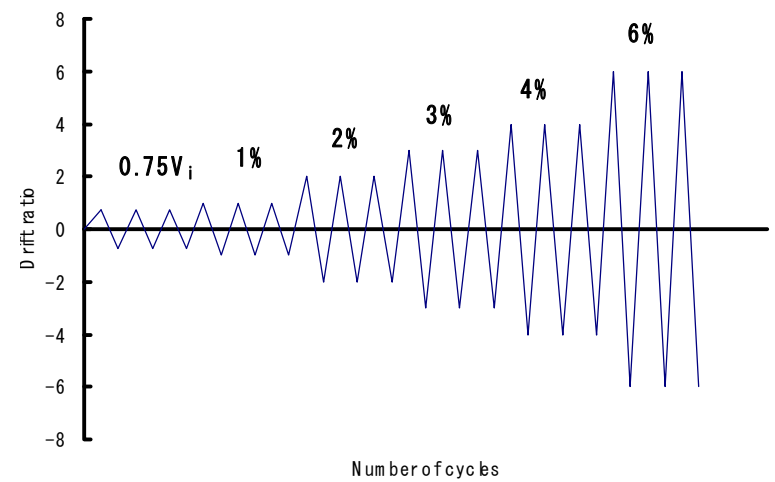

Fig. 4. Loading sequence

Reversed cyclic loading was applied to the specimens with a $10 \%$ axial load of the nominal axial capacity of the columns as shown in Fig. 3. The lateral cyclic load was applied under displacement control with three reversed cycles at each specified drift ratio in accordance with ACI 374.1-05 [7] as shown in Fig. 4. The lateral load was applied to the weak axis of the columns considering the actuator capacity of $2,000 \mathrm{kN}$. The test measurements included the applied actuator load and column deflection at the loading point. The strains on the crossties were measured and the measuring points were marked in the column sections as shown in Fig. 1. 


\section{Results of flexure tests}

\subsection{Overall behavior}

All specimens showed typical flexural behaviors such as the sequence of [flexural cracking][yielding of longitudinal bars]-[spalling of cover concrete]-[buckling of compression longitudinal bars]. In all specimens, the initial flexural cracks occurred at the $0.5 \%$ drift ratio. The longitudinal bars in tension yielded and diagonal shear cracks occurred at the $1 \%$ drift ratio. The lateral load at the $4 \%$ drift ratio was the maximum for all specimens. After the maximum load, the concrete covers began to be damaged and the buckling of longitudinal bars began in the compression side, which caused the strength degradation of the specimens. The strength degradation of FC progressed more rapidly than that of FM because the $90^{\circ}$ hooks opened toward the concrete cover and the compression bars of FC buckled earlier than those of FM. Fig. 5 shows the crack patterns of FC and FM specimens at the $6 \%$ drift ratio. Because the $90^{\circ}$ hooks of $\mathrm{FC}$ opend, the cover concrete of FC severely spalled and the crack width was wider than FM. Failure was defined as $15 \%$ reduction of the maximum load. The specimen $\mathrm{FC}$ failed at $6 \%$ drift ratio, whereas the specimen FM failed at $8 \%$ drift ratio. The other specimens of FC-1 and FMC behaved similarly to FC.

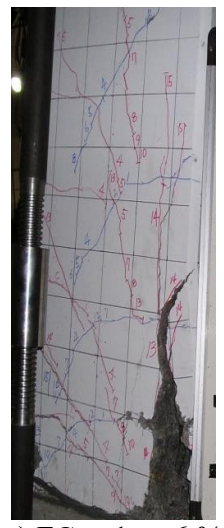

a) $\mathrm{FC}$ at $1 \mathrm{st}-6 \%$

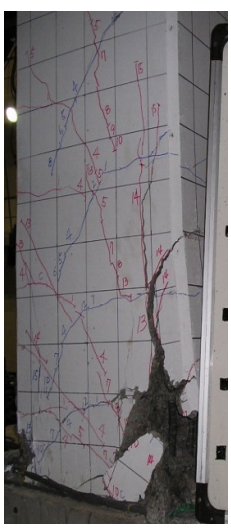

b) $\mathrm{FC}$ at $2 \mathrm{nd}+6 \%$

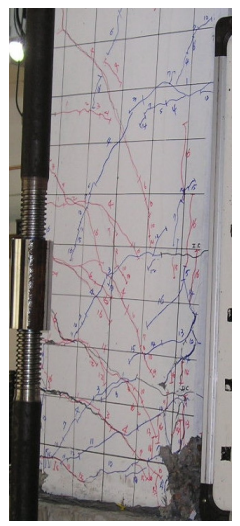

c) FM at $1 \mathrm{st}-6 \%$

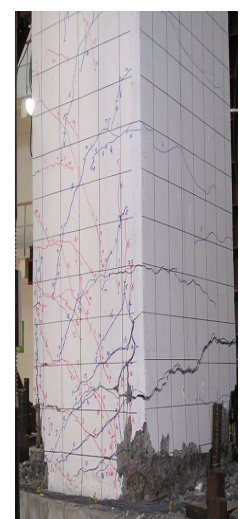

d) FM at 2 nd $+6 \%$

Fig. 5. Crack patterns of FC and FM at $6 \%$ drift ratio

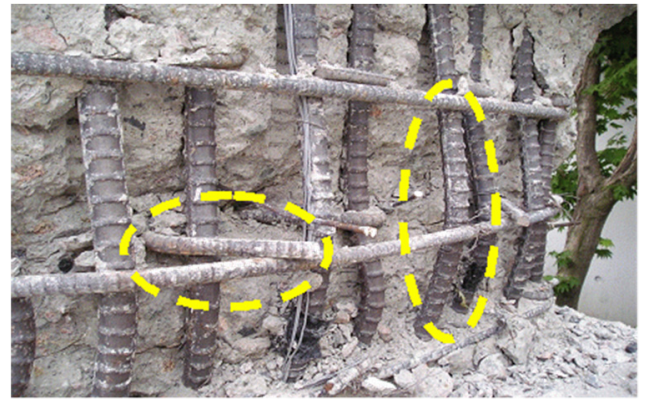

a) FC

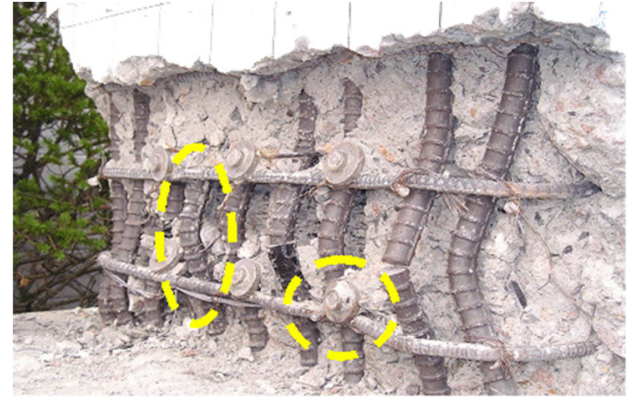

b) FM

Fig. 6. Buckling of the longitudinal reinforcing bars

The buckled longitudinal bars were shown in Fig. 6 where the cover concrete was intentionally removed. For FC, the $90^{\circ}$ hooks obviously opened as shown in Fig. 6(a) and they could not prevent the longitudinal bars from buckling. The buckling length of the longitudinal bars increased twice and the load resistance capacity rapidly decreased. However, the heads in FM could effectively enclose the hoops until the ultimate state as shown in Fig. 6(b) and the buckling length of the 
initial value was maintained until the ultimate state. This result made the different behaviors between FC and FM.

\subsection{Relationship between load and displacement}

The relationships between lateral load and lateral displacement are shown in Fig. 7. All specimens showed a typical flexural behavior; in particular, the yielding and maximum loads were notably similar for all specimens because the specimens conformed to the seismic-design requirements of ACI 318-14. No significant pinching was observed until failure because of the flexural behavior.

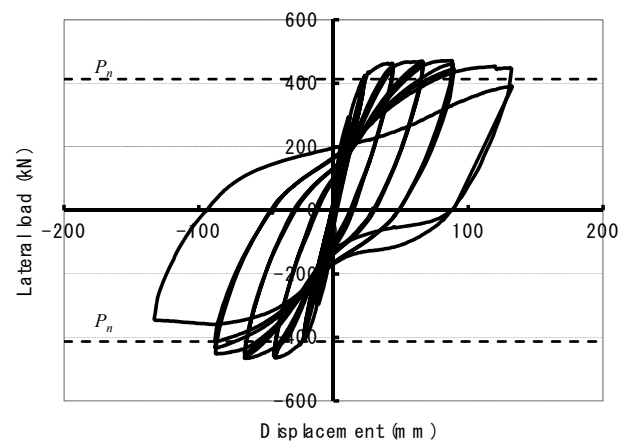

a) $\mathrm{FC}$

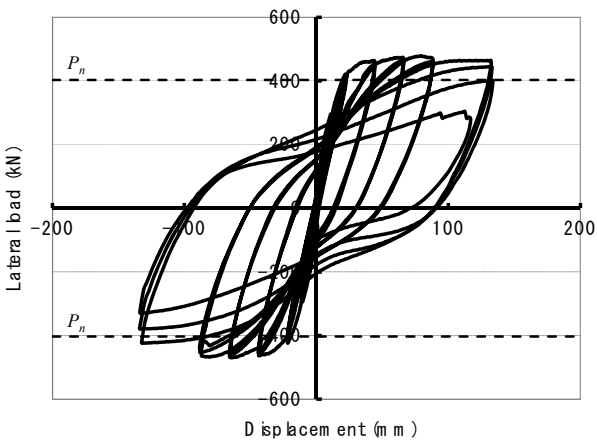

c) FMC

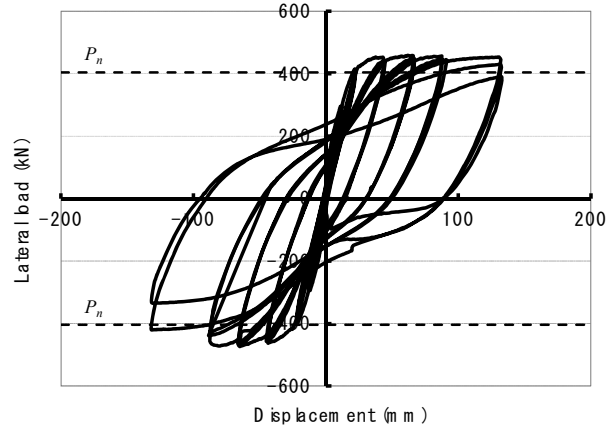

b) $\mathrm{FC}-1$

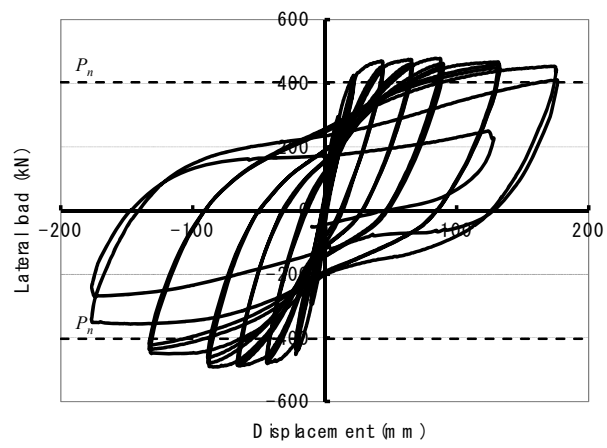

d) FM

Fig. 7. Relationships between lateral load and drift of the flexural tests

Table 1. Summary of the test results

\begin{tabular}{|c|c|c|c|c|c|c|c|c|c|}
\hline \multicolumn{2}{|c|}{ Specimens } & $P_{y e}, \mathrm{kN}$ & $P_{y t}, \mathrm{kN}$ & $P_{\max }, \mathrm{kN}$ & $P_{n}, \mathrm{kN}$ & $P_{\max } / P_{n}$ & $\Delta_{y}, \mathrm{~mm}$ & $\Delta_{u}, \mathrm{~mm}$ & $\Delta_{u} / \Delta_{y}$ \\
\hline \multirow{4}{*}{$\begin{array}{c}\text { Flexural } \\
\text { test }\end{array}$} & $\mathrm{FC}$ & 434.1 & 393.9 & 471.4 & 413.0 & 1.20 & 25.8 & 131.8 & 5.11 \\
\cline { 2 - 10 } & $\mathrm{FC}-1$ & 412.6 & 393.9 & 458.6 & 404.0 & 1.16 & 21.9 & 132.8 & 6.06 \\
\cline { 2 - 10 } & $\mathrm{FMC}$ & 411.6 & 393.9 & 479.2 & 403.0 & 1.22 & 22.6 & 133.8 & 5.92 \\
\cline { 2 - 10 } & $\mathrm{FM}$ & 423.4 & 393.9 & 478.2 & 403.0 & 1.21 & 21.5 & 176.2 & 8.20 \\
\hline \multirow{3}{*}{$\begin{array}{c}\text { Shear } \\
\text { test }\end{array}$} & $\mathrm{SC}$ & $1,129.9$ & 965.3 & $1,136.8$ & 967.4 & 1.18 & 20.3 & 33.0 & 1.62 \\
\cline { 2 - 9 } & SMC & $1,004.5$ & 965.3 & $1,146.6$ & 966.4 & 1.19 & 16.8 & 33.1 & 1.97 \\
\cline { 2 - 9 } & $\mathrm{SM}$ & $1,057.4$ & 965.3 & $1,102.5$ & 966.4 & 1.14 & 15.2 & 33.4 & 2.20 \\
\hline
\end{tabular}

* $P_{y e}$ and $P_{y t}$ are measured and calculated yield loads, respectively, $P_{\max }$ is a measured maximum load, $P_{n}$ is a nominal strength based on actual material properties, and $\Delta_{y}$ and $\Delta_{u}$ are lateral displacements at yield load and failure load, respectively.

There is little difference between specimens up to approximately $130 \mathrm{~mm}$ ( $6 \%$ drift ratio) in the hysteretic curves. FC failed at the 1 st cycle of $-6 \%$ drift ratio; FC- 1 maintained the load until the complete 2 nd cycle of $6 \%$ drift ratio; FMC maintained the load until the complete 3 rd cycle 
of $6 \%$ drift ratio; and FM maintained the load until the complete 2 nd cycle of $8 \%$ drift ratio. The measured and calculated strengths and the measured yield and ultimate displacements of all specimens are summarized in Table 1. The ductility factor, which is defined as the ratio of ultimate displacement $\left(\Delta_{u}\right)$ to yield displacement $\left(\Delta_{y}\right)$, of FM is much higher than that of FC as shown in Table 1. Although the anchorage types of crossties did not affect the load-carrying capacity, they affected the ductility of the columns. Considering the excellent observed behavior of FM and FMC, it is concluded that the heads were more effective as anchorages of the crossties than the conventional hooks in RC columns.

The envelope curves of FC and FM are shown in Fig. 8. The flexural cracking, bar yielding, and maximum loads are almost identical. However, the longitudinal bars in FC buckled before those in FM did because the $90^{\circ}$ hooks opened. The buckled longitudinal bars made the transverse reinforcement yielded; finally, the columns lost the load resistance.

\subsection{Energy dissipation comparison}

The cumulative displacement-dissipated energy curves are shown in Fig. 9. The $x$-axis represents the cumulative displacement that the specimen experienced, whereas the $y$-axis represents the dissipated energy. Until the 1 st cycle of $6 \%$ drift ratio (approximately $3000 \mathrm{~mm}$ cumulative displacement), all specimens had identical energy dissipation capacities. Although FC failed at the 1 st cycle of $6 \%$ drift ratio, FM maintained the load-resisting capacity until the $8 \%$ drift ratio; therefore, FM dissipated more energy as shown in Fig. 9. The energy dissipation capacities of FMC and FM show again that the heads can effectively confine the core concrete and prevent the longitudinal bars from buckling.

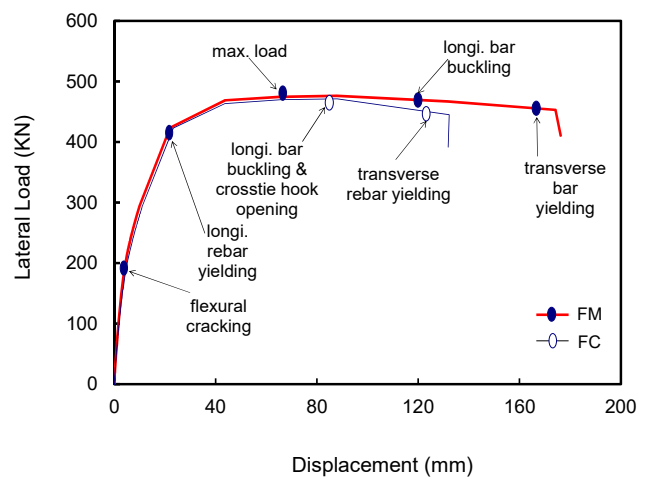

Fig. 8. Envelope curves of the relationship between lateral load and drift of FC and FM specimens

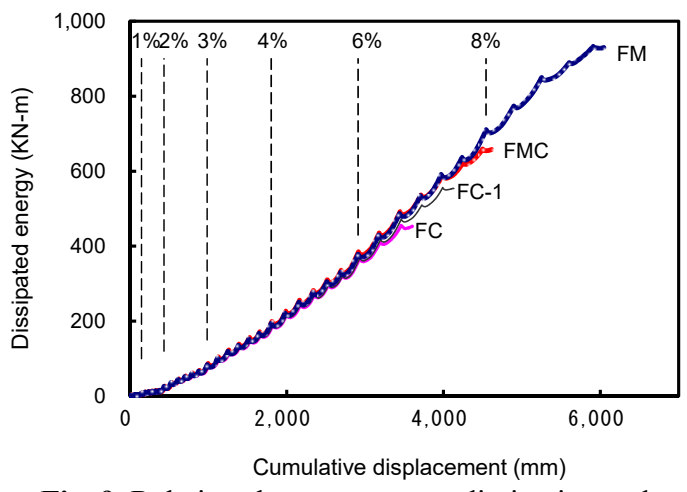

Fig. 9. Relations between energy dissipation and cumulative displacement of the flexural tests

\section{Results of shear tests}

\subsection{Overall behavior}

The SC, SMC and SM specimens are columns with low volumetric ratios of transverse bars, which were designed to fail in a shear mode. The behaviors of all columns are notably similar except the crack patterns. The initial flexural cracks occurred at the first loading. Diagonal shear cracks began at the $0.5 \%$ drift ratio. Although the columns were designed to fail in shear, the longitudinal bars yielded. Immediately after the longitudinal bars yielded, the maximum lateral load was developed at the $2.0 \%$ drift ratio, which was followed by diagonal cracks propagating to the top of the column and the decrease in strength. At the $3 \%$ drift ratio, the specimens significantly lost the load resistance. The shear failure mode dominated in all shear specimens.

Fig. 10 shows the crack patterns at $1.5 \%$ and $3.0 \%$ drift ratios. While many cracks with small 
widths are widely spread in SM, a few large cracks are concentrated in SC. It is considered that the headed bars confined the core concrete so effectively that only small cracks occurred at the overall column face.

\subsection{Relationship between load and displacement}

The relationships between lateral load and lateral displacement of the shear tests are shown in Fig. 11. The load-displacement relations indicate that all specimens showed a limited ductility such that all columns immediately failed after the maximum loads were reached. The yielding and maximum loads were notably similar for all specimens as shown in Table 1. Because of shear cracks, significant pinching was observed from the first loading.

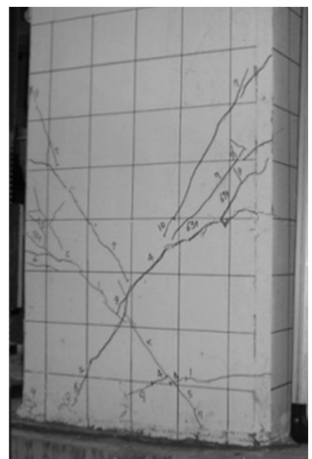

a) $\mathrm{SC}$ at $1.5 \%$

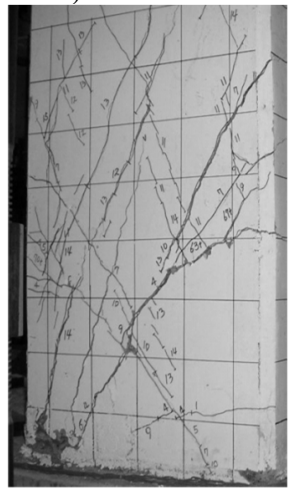

d) $\mathrm{SC}$ at $3.0 \%$

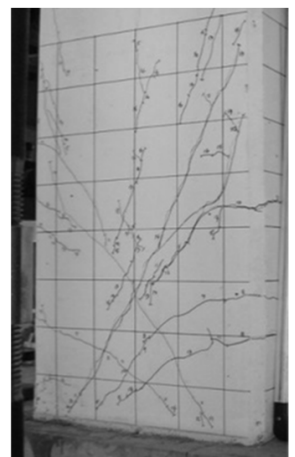

b) $\mathrm{SMC}$ at $1.5 \%$

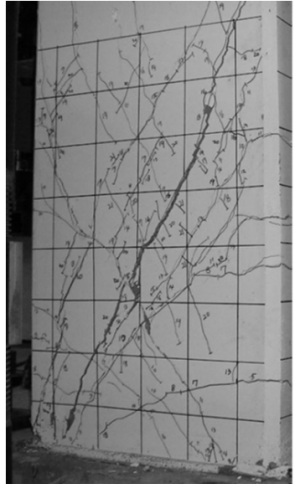

e) $\mathrm{SMC}$ at $3.0 \%$

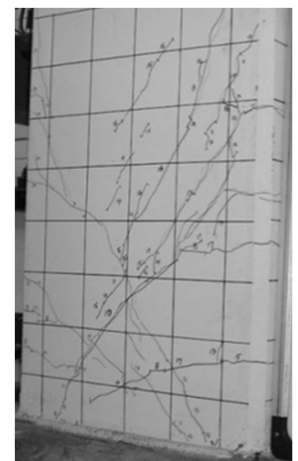

c) SM at $1.5 \%$

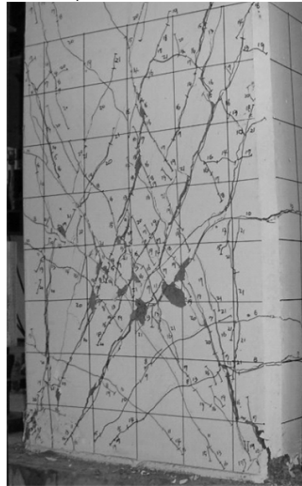

f) $\mathrm{SM}$ at $3.0 \%$

Fig. 10. Crack patterns of shear tests at the 1 st cycles of $1.5 \%$ and $3.0 \%$ drift ratios

All specimens failed at the first cycle of $-3 \%$ drift ratio. All specimens had almost identical yield and maximum strengths. After the longitudinal bars yielded, the maximum flexural strengths were developed. Shear failure was dominant in all columns but the specimens had higher flexural strengths than the nominal flexural strength by at least $14 \%$ as shown in Table 1 . The ductility factors $\left(\Delta_{u} / \Delta_{y}\right)$ are 1.62 and 2.20 for SC and SM, respectively. Considering the small values of the ductility factors, there is no meaningful difference in ductility between SC and SM.

The envelope curves of the shear tests are shown in Fig. 12. The flexural cracking, diagonal cracking, bar yielding, maximum, and failure loads are almost identical. The envelope curves show that the double headed bars and one-side headed bars can be effective alternatives to the standard hooked bars as crossties in RC columns. 


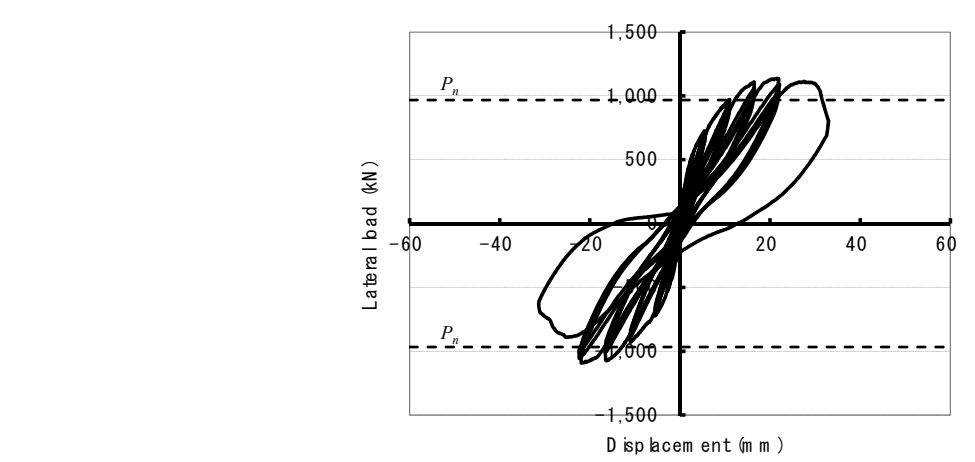

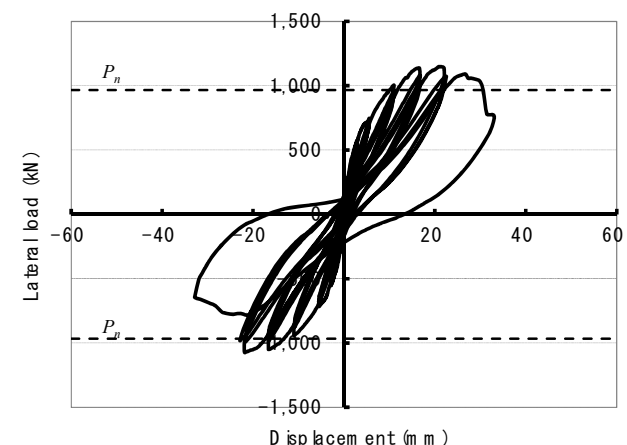

b) SMC

a) $\mathrm{SC}$

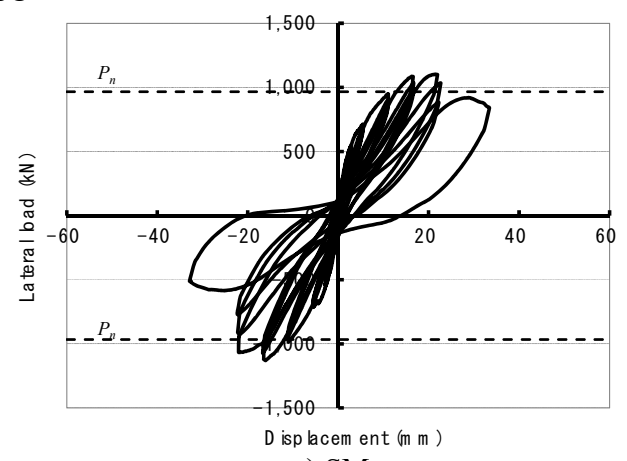

c) $\mathrm{SM}$

Fig. 11. Relationships between lateral load and drift of the shear tests

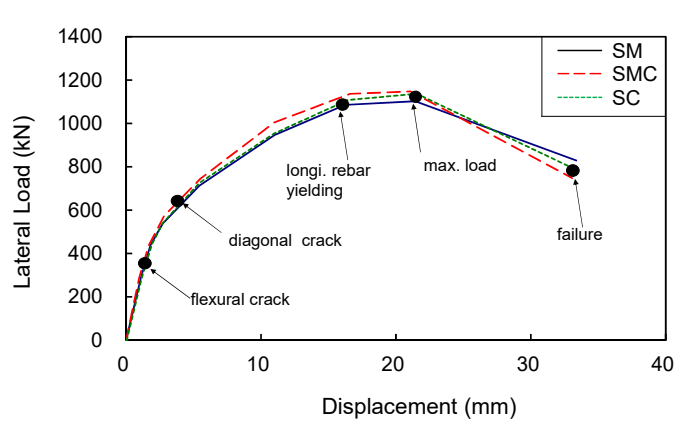

Fig. 12. Envelope curves of the relationship between lateral load and drift of the shear tests

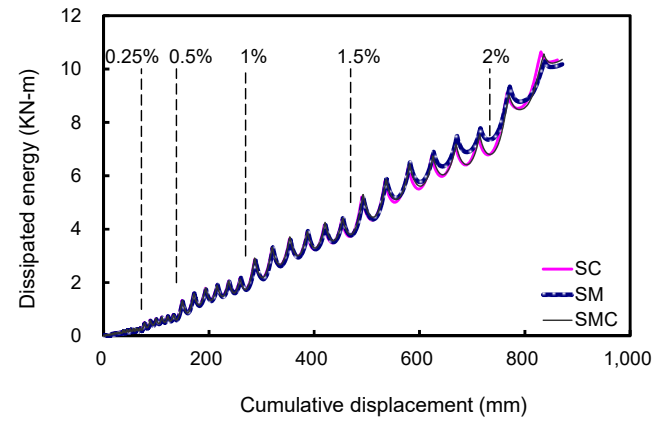

Fig. 13. Relations between energy dissipation and cumulative displacement of the flexural tests

\subsection{Energy dissipation comparison}

The cumulative displacement-dissipated energy curves of shear tests are shown in Fig. 13. Because all specimens show similar hysteretic behaviors, the dissipated energies of all specimens were almost identical.

\subsection{Strains of transverse reinforcement}

Fig. 14 shows the strains that were measured at the crossties. The measuring points are indicated in Fig. 1. The $x$-axis represents the cumulative displacement that the specimen experienced and the $y$-axis represents the strains. The crossties of SC with conventional hooks only yielded at the center, so the strains at both ends near the $90^{\circ}$ and $135^{\circ}$ hooks were relatively low. However, the crossties of SMC and SM yielded at both ends and the center as shown 
Fig. 14(b) and (c) at the $0.5 \%$ drift ratio. The measured strains show that the heads are more effective to develop the design strength of crossties than the conventional hooks. In addition, the crack patterns can be explained with the measured strains, such that the large cracks that are observed in $\mathrm{SC}$ can be attributed to the strain distribution.

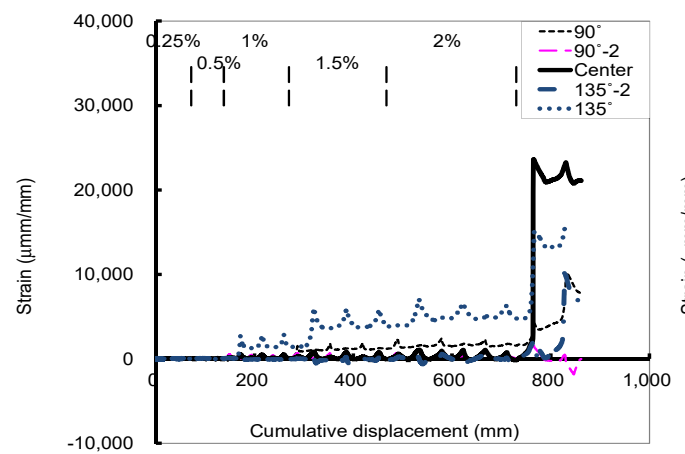

a) $\mathrm{SC}$

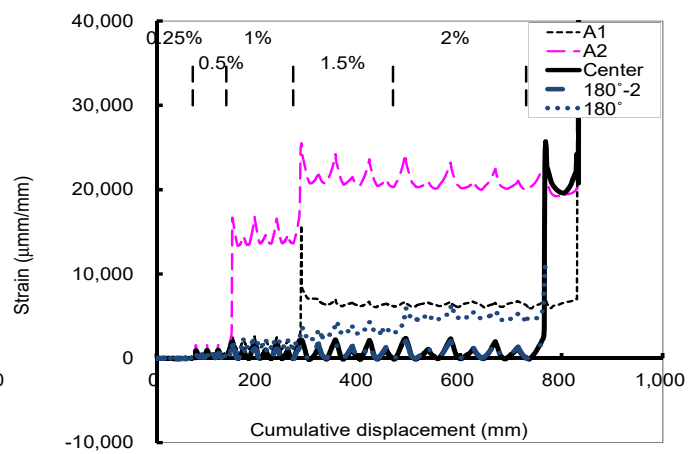

b) SMC

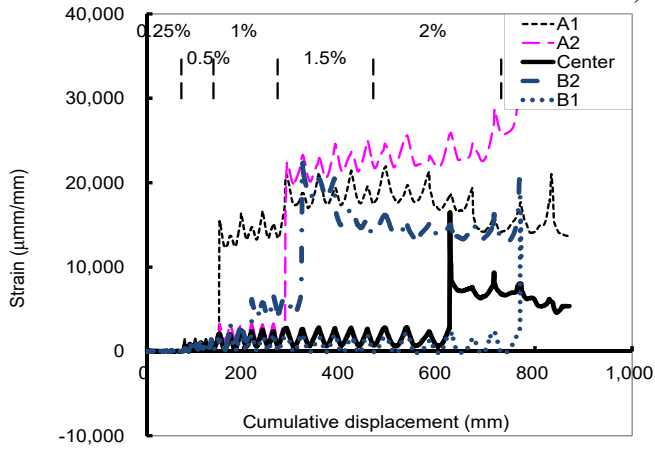

c) $\mathrm{SM}$

Fig. 14. Relations of the strain of a crosstie and cumulative displacement of the shear tests

\section{Conclusions}

Based on the experimental investigation on crossties that are anchored by heads in reinforced concrete columns, the following conclusions can be drawn:

1. The columns with double or one-sided headed shear reinforcement exhibit superior behavior in terms of ductility and energy dissipation capacity compared to those with conventional crossties.

2. The columns with headed shear reinforcement have approximately identical flexural and shear strengths as the columns with conventional crossties.

3. The column with double headed shear reinforcement that was designed to fail in a flexural mode maintained its flexural capacity until $8 \%$ drift ratio, whereas the column with conventional crossties failed at $6 \%$ drift ratio. After the cover concrete spalled, the $90^{\circ}$ hooks inevitably opened and the column longitudinal bars buckled. However, the heads could delay the buckling of the column bars up to $8 \%$ drift ratio.

4. Whether the hooks of crossties enclose the longitudinal bars or the hoops did not affect the strength and ductility of columns.

5. The crossties with one-side head and one-side $180^{\circ}$ hook exhibit almost similar behavior to the crossties with double heads. The crossties with one-side head and one-side $180^{\circ}$ hook can be a good alternative to the crossties with double heads.

6. For the columns that were designed to fail in a shear mode, the columns with the headed crossties had smaller crack widths than the columns with the conventional crossties because the 
headed crosstie well confined the core concrete under severe shear deformation.

\section{Acknowledgements}

This research was supported by the Basic Science Research Program through the National Research Foundation of Korea (NRF) funded by the Ministry of Education, Science and Technology (No. 2011-0013828). The authors wish to thank Boo Won B.M.S. Co. Ltd., Korea, for providing the headed bars used in the tests.

\section{References}

[1] Mitchell D., Cook W. D., Liu J. Confinement of columns and wall boundary elements using headed bars. Journal of Structural Engineering, Vol. 140, Issue 3, 2014.

[2] Ghali A., Youakim S. A. Headed studs in concrete: state of the art. ACI Structural Journal, Vol. 102, Issue 5, 2005, p. 657-666.

[3] Dilger W. H., Ghali A. Double-head studs as ties in concrete. Concrete International, Vol. 19, 6, p. 59-66.

[4] Youakim S. A., Ghali A. Ductility of concrete columns with double-head stud. ACI Structural Journal, Vol. 99, Issue 4, 2002, p. 480-487.

[5] ASTM A970/A970M-15, Standard Specification for Headed Steel Bars for Concrete Reinforcement. ASTM International, 2015.

[6] Building Code Requirements for Structural Concrete (ACI 318M-14) and Commentary (ACI 318RM-14). American Concrete Institute Committee 318, 2014.

[7] Acceptance Criteria for Moment Frames Based on Structural Testing and Commentary. American Concrete Institute Committee 374, 2005.

[8] ASMT A970-15: Standard Specification for Headed Steel Bars for Concrete Reinforcement. American Society of Testing and Materials, 2015.

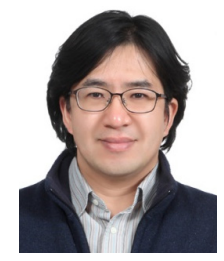

Taehun Ha received Ph.D. degree in Department of Architectural Engineering from Seoul National University, Seoul, Korea in 2004. Now he works as a Principal Research Engineer in Architectural Engineering Research Team at Daewoo Engineering and Construction Co., Ltd., Seoul, Korea. His current research interests include construction stage analysis of tall buildings, concrete creep and shrinkage, and as-built monitoring of structures.

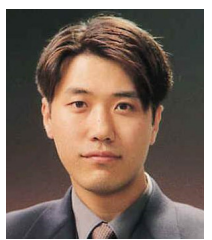

Sungho Lee received Ph.D. degree in School of Civil, Environmental and Architectural Engineering from Korea University, Seoul, Korea in 2016. Now he works as a Principal Research Engineer in Architectural Engineering Research Team at Daewoo Engineering and Construction Co., Ltd., Seoul, Korea. His current research interests include construction stage analysis of tall buildings, steel anchorage to concrete, and composite structures.

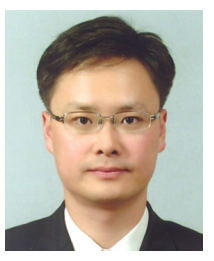

Sung-Chul Chun received Ph.D. degree in Department of Architectural Engineering from Seoul National University, Seoul, Korea, in 2007. Now he works as an Associate Professor in the Division of Architecture and Urban Design at Incheon National University, Incheon, Korea. His research interests include steel anchorage to concrete under cyclic loading, composite structures, and the seismic rehabilitation of reinforced concrete structures. 